\title{
ON THE LIFE ASSESSMENT OF A THROUGH- CRACKED WELDED TUBULAR T-NODE
}

\section{K. Brown}

Department of Mechanical Engineering, University of Glasgow, Glasgow G12 $8 Q Q$, Scotland

\section{ABSTRACT}

The tubular joints of offshore structures are subject to dynamic loading which causes initiation and propagation of fatigue cracks at the welded which intersections. When a through crack is detected, an assessment tubst be made on the remaining life and of the necessity to repair such a connection. From thin shell finite element analysis of a simple T-joint conn with dife imposition of peak static loads on a cracked the reduct of the loads to node will increase the possit.

\section{KEYWORDS}

Tubular joint, through crack, fatigue, tearing.

\section{INTRODUCTION}

The dosign of large offshore structures has involved the use of large tubular sections, resulting in complex $\mathrm{T}, \mathrm{K}, \mathrm{Y}$ and $\mathrm{X}$ nodes. The requirement for sections, resulting in complex data on stress elevation at such welded nodal joints led to a series of metric equations (Kuang and others, 1977. Wordsworth and section on both relating stress concentration factors (SCF actors defining the joint. Jacket structures (Fig. The combination of incipient undetected flaws in areas of high stress concentration and the dynamic nature of the wind, wave and current loads on such structures gives rise to fatigue damage. The initial propagation of surface flaws around a damaged intersection is often difficult to detect by divers especially if the node is encrusted with marine growth. The through-thickness crack and the more significant loss of stiffness is more thasily detected and it is this latter situation which is addressed in this paper. 
Damage in a node initiates as flaws such as "thumbnail" surface cracks and preads around the intersection at into the thick great into the thickness. The modelling of this situation requires $3-D$ finite element analysis or the use of a simpler shell analysis with "line springs" (Rice and Levy,1972). This latter approach is currently being pursued in order that estimates of initial crack propagation can be made. The later stage of crack propagation is related to the growth of through thickness cracks and this is analysed using a shell finite element approach by "unzil ing" the intersection and monitoring the change of compliance and energy. This stage can occupy about $60 \%$ of the joint life.

By calculating the compliance at different crack lengths, the stress intensity factor $K_{I}$ can be found as a function of crack length 'a' (Brown an alternating node is subject to the crack proparat and thus $\Delta \mathrm{K}_{\mathrm{I}}$, particuck propagation rate at any particular crack length can be for from the crack growth for any particular material

Fig. 1. Example of satellite platform for a similar loading sequence,

producing finally accelerated crack growth. But, a damaged joint has a reduced stiffness and in a highly redundant structure alternative load paths will be found to transmit applied loads to the foundations. The net result is that load transmission through a damaged joint will reduce.

At long crack lengths the possibility of tearing will increase. By computing the work done by the applied loads at particular crack lengths values of $y$ are found. Since any plasticity is very localised values of $y$ and $J$ are virtually identical. As any static load increases on the node with any particular crack length, the value of J increases until a value of $J_{C}$ is reached, at which tearing will initiate. At small crack lengths of $J_{C}$ tearing load is well beyond any design loading and is liable to cause wide spread yielding. However as the crack length increases, the critical wideis less than the design load and crack length increases, the crical plastic flow. The fause only very localised structure which crack propacion 1979). Propagation - but this is not discussed further here (Paris and others,

In order to develope the technique, a relatively simple $T$ joint was selected. mes (Irvine, correspond to a nodal joint used in other experimental prograaxial and bending ; Wylde and McDonald, 1981). The two in-plane loads, axial and bending (I.P.B.) were analysed, in addition to an out-of-plane

The results of reduced stiffness were applied to a sample 2-D plane beam 17ucture to illustrate load shedding from a damaged joint (Brown, 1984). Hlthough the whole analysis is essentially two dimensional the technique child be generalised to three dimensions and the principles scaled up to a 11 size gentre he case of the development of the parametric equations, a complete series of racked node geometries will be required.

Loading.

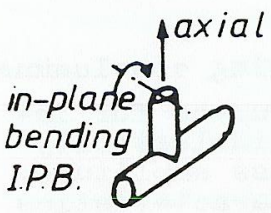

$B$

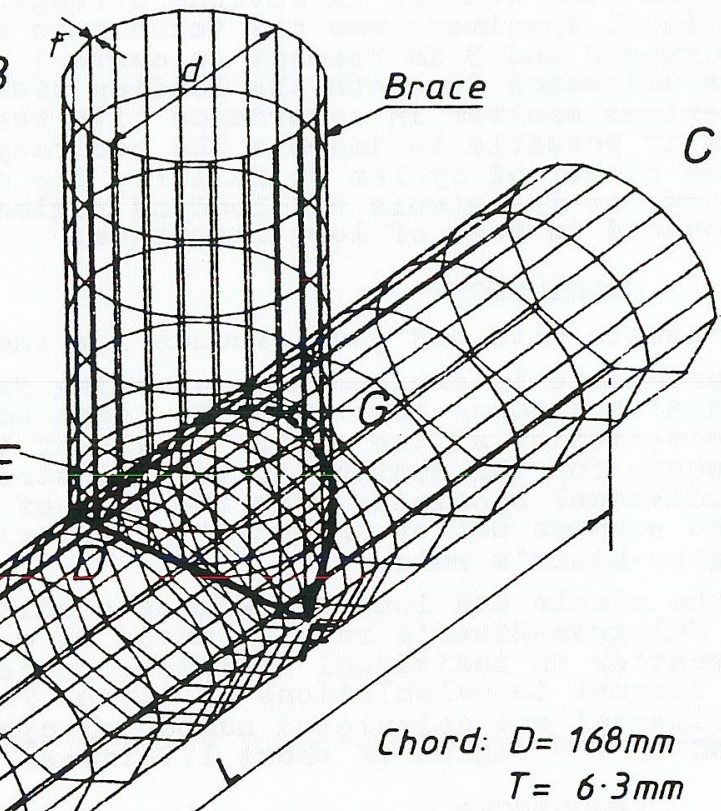

A

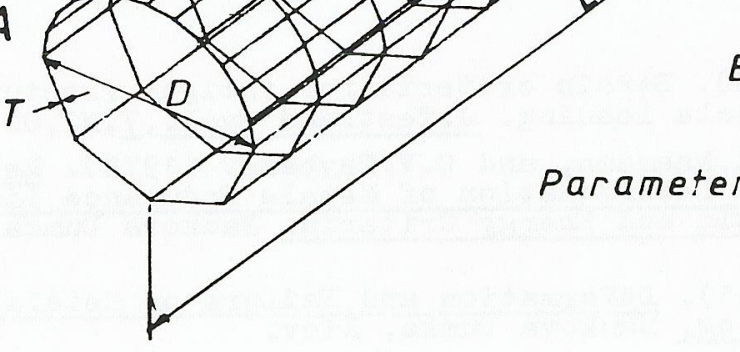

Brace: $d=968 \mathrm{~mm}$

$t=4.47 \mathrm{~mm}$

$$
\begin{aligned}
& s: \alpha=\frac{2 L}{D}=10 \\
& \beta=\frac{d}{D}=1.0 \\
& \gamma=\frac{D}{2 T}=13.33 \\
& \tau=\frac{t}{T}=0.71
\end{aligned}
$$




\section{FINITE ELEMENT ANALYSIS}

The finite element idealisation of the $T$ node is illustrated on Fig. 2 along with the dimensions. The loading was applied at brace end $B$ with the boundary conditions at chord ends $A$ and $C$ being encastré. The of the effect of the effect of mesh size on stress concentration factors.

The 'unzipping' of the node was achieved merely by progressively separating nodes of the lower elements of the brace at the intersection from the corre ponding nodes on the chord. This was done symmetrically about $D$ and solutions for 5, 9. 11 (halfway E D F), 15 and 17 nodes separated were produced. No special crack-tip elements were used as they were deemed to little effect the response of the loading end $B$, at which stiffness and work values were computed.

The node mesh comprised thin shell elements and the solutions were run using FLASH2 (Walder and Green 1982) (Finite element Analysis of SHell, version with an optimiser and run on an ICL2976 at the University $\bar{f}$. run took around $550 \mathrm{cpu}$ secs., there being 528 elvers three different loadings (Axial, IPB and OPB).

\section{RESULTS}

\section{Stress Concentration Factors (SCF):}

The SCF is calculated as the highest stress at the interface normalised against a nominal stress. The nominal stress is

\section{$\frac{\text { Applied Load }}{A_{\text {brace }}}$ for axial Loading or $\frac{\text { Applied Moment }}{Z_{\text {brace }}}$ for IPB}

where $A=$ cross-section area, $Z$ = section modulus

The highest stress exists at the point D (Fig. 2) on the chord at the brace/chord intersection for this node with axial and IPB loading. Extrapolation from element centroids to the intersection is required for Extra values. The stress values used were the summation of requed for stress stresses and expressed as an effective stress where (in principal bending

$$
\bar{\sigma}=\sqrt{\frac{1}{2}\left[\left(\sigma_{1}-\sigma_{2}\right)^{2}+\left(\sigma_{2}-\sigma_{3}\right)^{2}+\left(\sigma_{3}-\sigma_{1}\right)^{2}\right]}
$$

Comparison of the calculated SCF's with those from the parametric equations of Kuang (1977) and Smedley and Wordsworth (1978) is given in Table 1. Also given are experimental values as found by Irvine (1981).

TABLE 1 Comparison of S.C.F.

\begin{tabular}{|l|c|c|c|c|}
\hline Loading Source & Kuang & $\begin{array}{c}\text { Smedley \& } \\
\text { Wordsworth }\end{array}$ & $\begin{array}{c}\text { Irvine } \\
\text { (Experimenta1) }\end{array}$ & $\begin{array}{c}\text { This } \\
\text { Analysis }\end{array}$ \\
\hline Axia1 & 3.5 & 4.3 & 3.7 & 3.3 \\
\hline IPB & 2.6 & 2.6 & - & 3.5 \\
\hline
\end{tabular}

The variation in Table I illustrates very clearly the difficulty of calculating SCF's. The node geometry is at the validity limits of the parametric equations.

\section{Compliance of Cracked Node}

From each of the five cracked solutions the axial and IPB stiffness were calculated as :

$$
\begin{aligned}
& \mathrm{C}_{\mathrm{ax}}=\frac{\delta}{\mathrm{F}} \text { where } \begin{array}{l}
\mathrm{F}=\text { applied force on brace } \\
\delta=\text { average axial displacement of brace en }
\end{array} \\
& \text { and } C_{\theta}=\frac{\theta}{M} \text { where } \begin{aligned}
M & =\text { Applied moment on brace }
\end{aligned}
\end{aligned}
$$

The flexibility of the chord was taken into account in each case.

Where $U$ is the work done by the applied load, for a crack length 'a' $y$ is Where $U$ as $y^{\prime}=\frac{\partial U}{\partial a}=\frac{K_{I}{ }^{2}}{E}$. $t$ in plane stress.

This results finally in

$$
\frac{K_{I}}{P}\left(\text { or } \frac{K_{I}}{M}\right)=\sqrt{\frac{\partial}{\partial a}\left(\frac{E C}{2 t}\right)} \text { where compliance } C=C_{a x} \text { or } C_{\theta}
$$

The graphs of $\frac{E C}{2 t}$ and $\frac{K_{I}}{P}$ against crack lengths are shown in Fig. 3 .

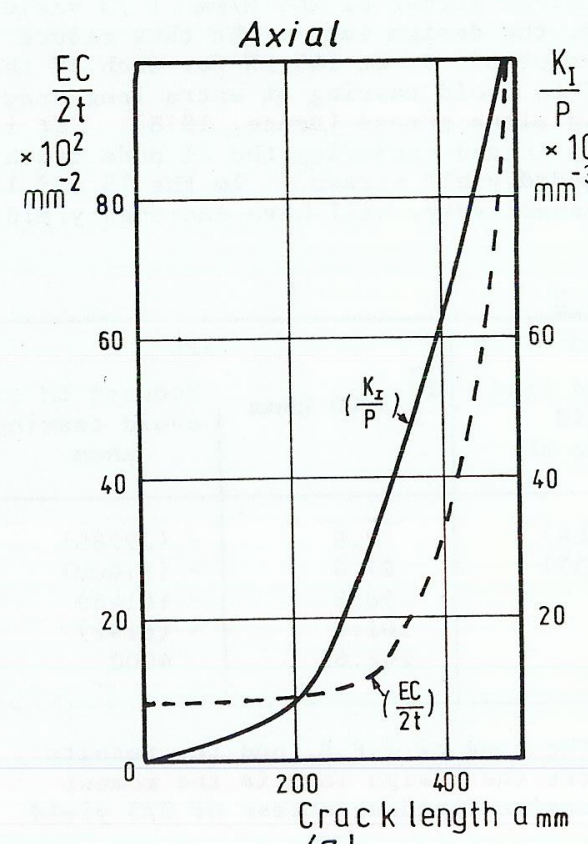

(a)

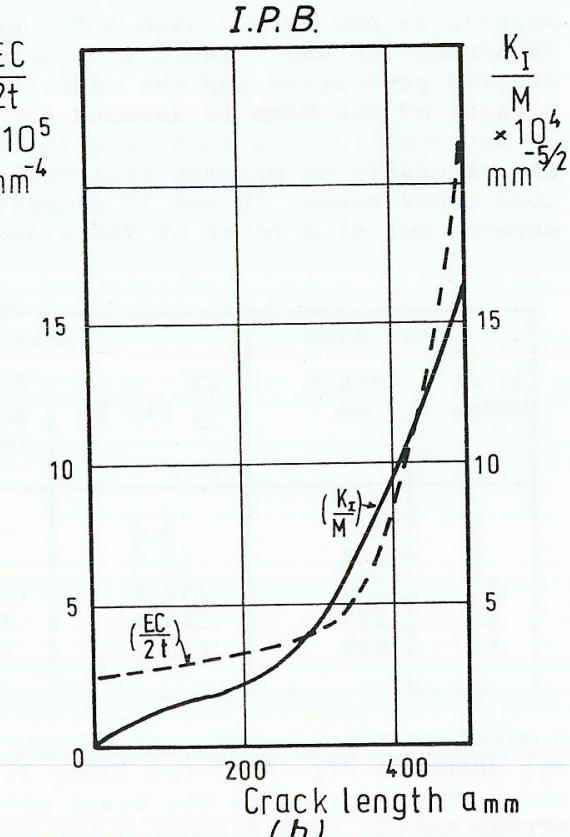

(b)
Fig. 3. Evaluation of stress intensity factor 
From these graphs it can be seen that for a crack of length $100 \mathrm{~mm}$ the value of $\mathrm{K}_{\mathrm{I}} / \mathrm{P}=3.35 \times 10^{-3} \mathrm{~mm}^{-3 / 2}$ For a tube of the given dimension, a load $\mathrm{P}$ of $230 \mathrm{kN}$ will give a nominal axial stress of $98 \mathrm{~N} / \mathrm{mm}^{2}$ (about one third yield stress). Thus the value of $\mathrm{K}_{\mathrm{I}}$ equals $24.38 \mathrm{MNm}^{-3 / 2}$. If the loading alternated 0 to $230 \mathrm{kN}$, the value of $\Delta \mathrm{K}_{\mathrm{I}}=24 \mathrm{MNm}^{-3} / 2$ would be put into the crack propagation curve and produce a crack growth rate.

Similarly for the same crack $100 \mathrm{~mm}$ in length $K_{I} / M=1.91 \times 10^{-4} \mathrm{~mm}^{-5 / 2}$. moment of $9000 \mathrm{kNmm}$ would give a nominal maximum bending stress of $93 \mathrm{~N} / \mathrm{mm}^{2}$ and if this moment were applied to the cracked node a $\mathrm{K}_{\mathrm{I}}$ value of $54 \mathrm{MNm}-3 / 2$ would result.

\section{Tearing}

When the cracked node is progressively statically loaded, the pre-dominantly elastic structure will respond as in Fig. 4(a) under an axial load. At any particular load, say $1 \mathrm{kN}$, the work done by the load $U=\frac{1}{2} P \delta$ increases with increasing crack length due to the greater compliance. If U is cross plotted onto Fig. 4(b) against crack length, the gradient of this graph give a value of $t \times y=\partial U / \partial a$ at any particular $y$

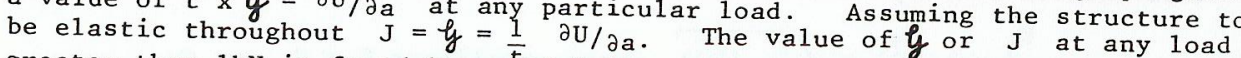
greater than $1 \mathrm{kN}$ is found by muftiplying the gradient value by the square of $143 \mathrm{~mm}$. At $70 \mathrm{kN}, \partial \mathrm{U} / \partial_{\mathbf{a}}=70^{2} 0.00155=7.6 \mathrm{Nmm} / \mathrm{mm}$ leading to $\mathrm{J}=1.7 \mathrm{~N} / \mathrm{mm}$.

The value of axial load to produce a nominal stress of $200 \mathrm{~N} / \mathrm{mm}^{2}\left({ }^{2} / 3\right.$ yield stress) is $460 \mathrm{kN}$ and with a SCF of 3.3 , the design load might thus reduce to around $140 \mathrm{kN}$. Table 2 shows the value of $\mathrm{J}$ at $140 \mathrm{kN}$ for each of the cracked geometries and the reduced load to avoid tearing at extra long the A value of $120 \mathrm{~N} / \mathrm{mm}$ is assumed for $\mathrm{J}_{\mathrm{C}}$ in plane stress (Druce, 1978) of interest to note that on solutions up to and including the 11 node the stress in no element will have exceeded yield stress. node crack cases, 30 and 70 elements respectively, will have exceeded yield stress, out of a total of 528 elements.

\begin{tabular}{|c|c|c|c|c|c|}
\hline \multicolumn{2}{|c|}{ Crack Size } & \multicolumn{2}{|c|}{ Axia1 Load } & \multicolumn{2}{|r|}{ IPB } \\
\hline $\begin{array}{l}\text { No of } \\
\text { Nodes }\end{array}$ & $\begin{array}{l}\text { Length } \\
\mathrm{mm}\end{array}$ & $\mathrm{J}] 140 \mathrm{kN}$ & $\begin{array}{l}\text { Reduced load } \\
\text { to avoid } \\
\text { tearing kN }\end{array}$ & $\mathrm{J}] 5700 \mathrm{kNmm}$ & $\begin{array}{c}\text { Reduced BM to } \\
\text { avoid tearing } \\
\mathrm{kNmm}\end{array}$ \\
\hline $\begin{array}{r}5 \\
9 \\
11 \\
15 \\
17\end{array}$ & $\begin{array}{l}143 \\
258 \\
320 \\
374 \\
498\end{array}$ & $\begin{array}{r}6.8 \\
12.3 \\
198.6 \\
344.6 \\
860.8\end{array}$ & $\begin{aligned}- & (588) \\
- & (437) \\
109 & \\
82 & \\
52 & \end{aligned}$ & $\begin{array}{c}7.9 \\
27.6 \\
58.8 \\
101.7 \\
242.62\end{array}$ & $\begin{array}{l}-(22286) \\
-(11800) \\
-(8143) \\
-(6192) \\
\quad 4000\end{array}$ \\
\hline
\end{tabular}

A similar analysis was carried out for the case of I.P.B. and the results are shown in Fig. 4(c) and Table 2. Here the design load is the moment stress taking into account a

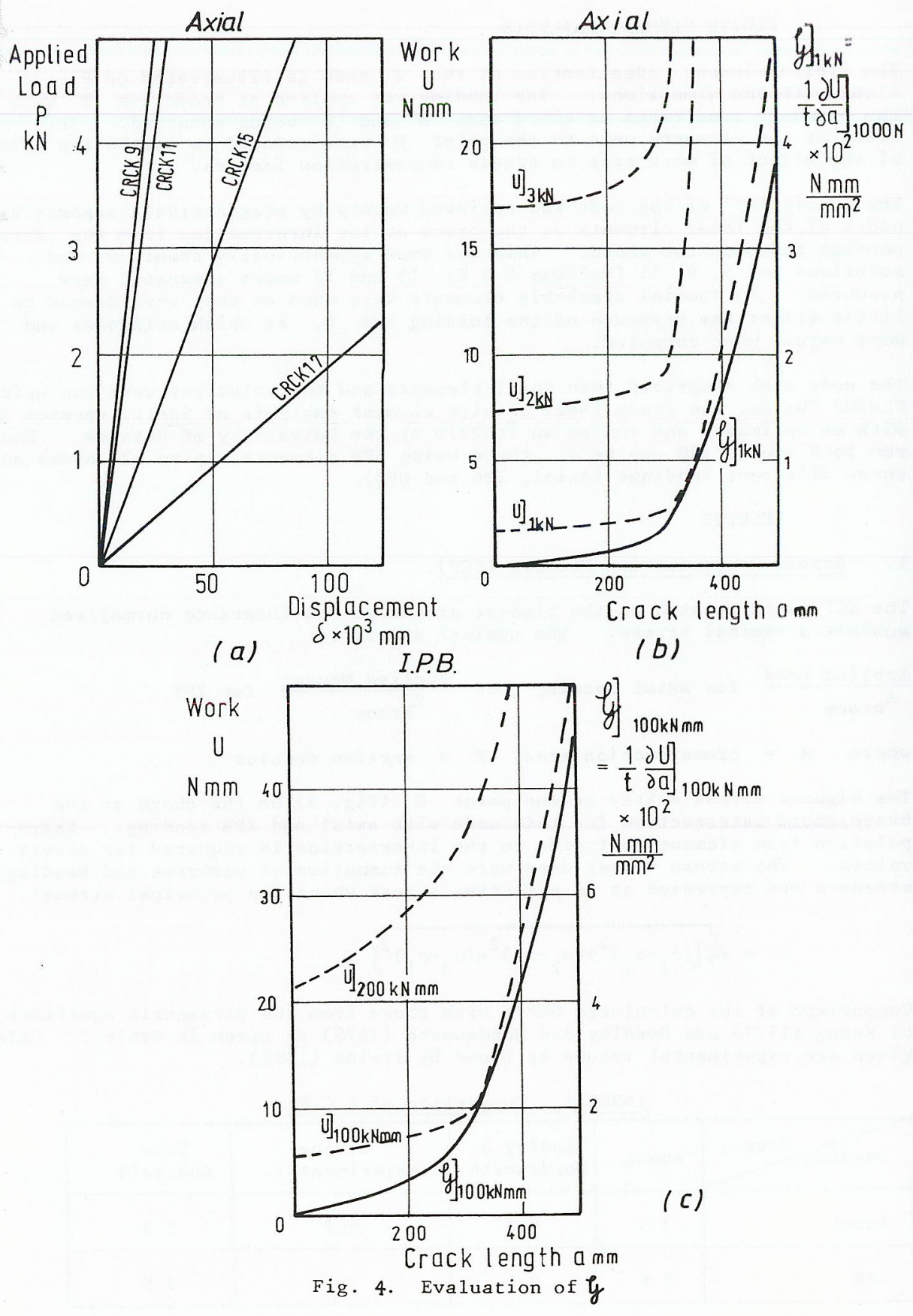


In Table 2, the likelihood of tearing is shown up to be significantly greater in axial loading than in I.P.B. It should of course be remembered that in ituent vales ituent values of $y$ (or $\mathrm{J}$ ) should be added, and the sum compared with $\mathrm{J}_{\mathrm{C}}$.

One of the more difficult parts of the above procedure is in the estimating of the gradient of the graph of U vs a. This is especially critical sinc this value at $1 \mathrm{kN}$ or $100 \mathrm{kNmm}$ is multiplied by the square of the working or design load. Two curve fitting routines were tried - a polynominal fit a a fast Fourier transform (FFT) - but neither was completely satisfactor an It is thought that a truncated exponental series could produce a betory. function.

CONCLUSIONS

The procedure illustrated above refers specifically to a T-joint of particula nodal joint and subject to in-plane loading. However the performance of any fashion. The purpose of the maining life potential of a significantly to find a way to assess the reproportion of the life is spent eicantly cracked joint. This significant tearing and an attemt has been tearing.

ACKNOWLEDGEMENTS

Most of this work was carried out under the S.E.R.C. Marine Technology Grant No. GR/B/2184.3. Acknowledgements are also due to the University of Glasgow for the computing facilities in the running of FLASH2.

Thanks are due to Mr. Q. Muir and to Dr. John Hancock and Dr. Michael Cowling for their assistance and helpful discussions.

\section{REFERENCES}

Brown, D.K., Hancock, J.W. and Green, D.R. (1984). On the finite element analysis of a welded tubular T-joint with a through-thickness crack. 3rd Int. Conf. on Num. Meth. in Frac. Mechs., Swansea.

Druce, S.G. (1981). Effect of specimen geometry on the characterisation Of ductile crack extension in C-Mm steel. 5th Int. Conf. on Fracture.

Review of stress analysis techniques used in UKORSP. Kuang, A.B., Patigue in offshore structural steels, I.C.E. London. pps 47-57. concentration in tubular joints. Stress Paris, P.C., Tada, H., Ernst, H. and Zoc. Petroleum Engs. J., pps 287-299. investigation of tearing instability ther, A. (1979): Initial experimental A.S.T.M. S.T.P. 668 p. 251 . Elastic Plastic Fracture, ice, J R. and Levy, $\mathrm{N}$. (1972)

elarthrough surface crack in an Walder, U. and Green. App. Mech., Trans. A.S.M.E. Vol. 39, p.185. STATIK. The finite element programs FLASH2 and Wordsworth, Ant. Conf. Finite Element Methods. Shanghai.

ordsworth, A.C. and Smedley, G.P. (1978). Stress concentrations at unstiffened tubular joints. European offshore Steels Research Seminar, paper 31. and stiffness measurements (1981). Modes of fatigue crack development in offshore Structural Steels, I.C.E. London, pps 79-88. 